\title{
PERANCANGAN SISTEM INFORMASI PENILAIAN KINERJA PROMOTOR TERHADAP PRODUCT KNOWLEDGE MENGGUNAKAN METODE KEY PERFORMANCE INDICATOR (STUDI KASUS : PT. WORLD INNOVATIVE TELECOMMUNICATION)
}

\author{
Genesis Angelia' $^{1}$, Petrus Sokibi ${ }^{2}$, Rifqi Fahrudin ${ }^{3}$ \\ Universitas Catur Insan Cendekia \\ Jl. Kesambi 202, Kota Cirebon, Jawa Barat Tlp : (0231) 220250 \\ e-mail : angeliagenesis22@gmail.com ${ }^{1}$, petrus.sokibi@cic.ac.id², rifqi.fahrudin@ cic.ac.id ${ }^{3}$
}

\begin{abstract}
ABSTRAK
Oppo adalah perusahaan yang bergerak dibidang smartphone. Dalam memasarkan produk, perusahaan memerlukan promotor dalam membantu user. Oleh sebab itu promotor adalah ujung tombak perusahaan dalam penjualan produk. Dalam meningkatkan penjualan produk, promotor harus paham mengenai produk yang dijualnya. Dalam meningkatkan kualitas product knowledge promotor, perusahaan mengadakan training. Namun pada saat melakukan penilaian product knowledge trainer mengalami kendala karena belum adanya sistem penilaian digital. Dari hasil penelitian, adanya sistem yang efektif dan efisien bagi promotor yaitu promotor dapat melihat hasil penilaian dari setiap kriteria sedangkan untuk trainer yaitu mempermudah dalam melakukan penilaian dan regional manager dapat melihat hasil kinerja promotor terhadap product knowledge. Selain itu, penelitian ini menghasilkan terbentuknya penilaian KPI dilakukan setiap 3 bulan ketika ada produk baru. Kriteria yang dihasilkan dalam KPI adalah kuesioner, probing, komparasi dan penjualan. Setiap kriteria memiliki bobot yaitu 10 untuk kuesioner, 30 untuk probing, 10 untuk komparasi dan 50 untuk penjualan. Penerapan metode KPI dapat menunjang pengambilan keputusan penilaian product knowledge terhadap kinerja promotor. Setiap promotor yang mendapatkan skor KPI 100 akan mendapatkan reward sebesar Rp.200.000 dan sertifikat.
\end{abstract}

Kata Kunci: Sistem penilaian, KPI, Kinerja promotor.

\begin{abstract}
Oppo is a company engaged in the smartphone sector. In marketing products, companies need promoters to help users. Therefore, the promoter is the spearhead of the company in product sales. In increasing product sales, promoters must understand the products they sell. In improving the quality of product knowledge promoters, the company held training. However, when evaluating product knowledge trainers, there are problems because there is no digital assessment system. From the results of the study, there is an effective and efficient system for promoters, namely the promoter can see the results of the assessment of each criterion, while for the trainer it is easier to make assessments and regional managers can see the results of the promoter's performance on product knowledge. In addition, this study resulted in the formation of KPI assessments carried out every 3 months when there were new products. The resulting criteria in the KPI are questionnaires, probing, comparisons and sales. Each criterion has a weight of 10 for the questionnaire, 30 for probing, 10 for comparison and 50 for sales. The application of the KPI method can support product knowledge assessment decisions on promoter performance. Every promoter who gets a KPI score of 100 will get a reward of IDR 200,000 and a certificate.
\end{abstract}

Keywords: Assessment system, KPI, Promoter performance.

Perancangan Sistem Informasi Penilaian Kinerja Promotor terhadap Product Knowledge Menggunakan Metode Key Performance Indicator (Studi Kasus : PT. World Innovative Telecommunication)-

(Genesis Angelia, Petrus Sokibi, Rifqi Fahrudin) 


\section{PENDAHULUAN}

Promotor adalah ujung tombak perusahaan untuk memasarkan produk. Dalam menjual produk, hal pertama yang diperlukan adalah harus mengenal baik bagaimana spesifikasi produk atau bisa dikatakan dengan product knowledge. Untuk menunjang pengetahuan promotor dalam product knowledge maka promotor harus mengikuti training produk yang diberikan oleh perusahaan selama 3 hari melalui trainer. Promotor yang sudah mengikuti training wajib mengikuti test yang berikan perusahaan dengan datang ke kantor sesuai dengan jadwal yang sudah ditentukan oleh trainer. Soal test menggunakan google form yang di share link di grup training. Pengujian product knowledge dibagi menjadi dua test yaitu test product knowledge dan test role play mengenai handphone Oppo Reno 5F yang diadakan pada periode Maret 2021.

Indikator dalam sistem penilaian yaitu kuesioner, probing, komparasi dan penjualan. Hasil nilai dapat dijadikan sebagai tingkat keberhasilan kinerja promotor. Dalam pencapaian kinerja promotor maka dibutuhkan metode KPI (Key Performance Indicator) adalah sebagai proses penilaian kinerja yang diberi target tertentu, sehingga presentase pencapaian dapat diperoleh berdasarkan rating. Hasil dari pencapaian kinerja akhir promotor digunakan sebagai tolak ukur dalam pemberian reward.

\section{KAJIAN PUSTAKA}

1. Pengukuran Kinerja

Pengukuran kinerja merupakan satu prinsip manajemen fundamental. Ada ungkapan mengatakan: "you can't manage anything unless you measure it" or "what gets measured gets done." Ungkapan lain mengatakan: "jika kamu tidak dapat menentukan kinerja , kamu tidak dapat mengukurnya. Oleh karena itu dalam pemahaman tentang pengukuran kinerja, perlu memahami kinerja. Karyawan perlu melihat hubungan antara "what they do" dan " the outcomes". Itu dapat diketahui melalui pengukuran kinerja (performance measurement). Penilaian kinerja karyawan harus dilakukan dengan adil, realistis, valid dan relevan dengan pekerjaan yang dilakukan karyawannya, serta harus bebas dari subjektifitas. Penilaian kinerja karyawan dapat dilakukan untuk memberi perhargaan kepada seorang karyawan yang berkinerja baik sesuai dengan kriteria penilaian yang telah ditentukan perusahaan.[1]

2. Key Performance Indicator (KPI)

Key Performance Indicator (KPI) merupakan bagian tak terpisahkan dari Sistem Manajemen Kinerja yang diimplementasikan dalam sebuah organisasi atau perusahaan. Dengan menerapkan Sistem Manajemen Kinerja, organisasi berupaya untuk memastikan agar arah pengembangan organisasi. Selain itu organisasi harus menetapkan KPI yang tepat agar pencapaian kinerja organisasi dapat terukur sesuai dengan tujuan organisasi yang tertuang dalam rencana strategi organisasi [2].

3. Website

Website dapat diartikan sebagai kumpulan halaman yang menampilkan informasi data teks, data gambar, data animasi, suara, video dan atau gabungan dari semuanya, baik yang bersifatstatis maupun dinamis yang membentuk satu rangkaian bangunan yang saling terkait, dimana masing-masing dihubungkan dengan jaringan-jaringan halaman (hyperlink) [3].

4. MySQL

MySQL adalah sebuah program database server yang mampu menerima dan mengirimkan datanya dengan cepat, multiuser serta menggunakan perintah standar SQL. MySQL memiliki dua bentuk lisensi, yaitu FreeSoftware dan Shareware. MySQL yang biasa digunakan adalah MySQL Free Software yang berada di bawah lisensi GNU/GPL (General Public License). Sebagai database server yang free, artinya MySQL dapat secara bebas digunakan untuk kepentingan pribadi atau usaha. Selain sebagai server, MySQL dapat juga berperan sebagai client sehingga sering disebut database client - server [4].

5. PHP

PHP (atau resminya php: hypertext preprocessor) adalah skrip bersifat serverside yang ditambahkan ke dalam html. PHP sendiri merupakan singkatan dari personal home page tools. Skrip ini akan membuat suatu aplikasi dapat diintegrasikan ke dalam $\mathrm{html}$ sehingga suatu halaman web tidak lagi bersifat statis, namun menjadi bersifat dinamis. Sifat server side berarti pengerjaan kode program dilakukan di server, baru kemudian hasilnya dikirimkan ke browser [5]. 
6. UML

Unified Modeling Language (UML) merupakan standard modeling language yang terdiri dari kumpulan-kumpulan diagram, dikembangkan untuk membantu para pengembang sistem dan software agar bisa menyelesaikan tugas-tugas [6].

\section{METODE PENELITIAN}

\subsection{Metode Pengumpulan Data}

Adapun pengumpulan data yang dilakukan untuk menunjang penelitian ini diantaranya:

1. Observasi

Pada penelitian ini penulis melakukan pengamatan langsung dengan mengamati situasi yang terjadi di PT. World Innovative Telecommunication mengenai penilaian kinerja promotor terhadap product knowledge.

2. Studi Literatur

Studi literatur adalah cara yang dipakai untuk menghimpun data-data sumber-sumber yang berhubungan dengan topik yang diangkat dalam suatu penelitian. Studi literatur bisa dapat dari berbagai sumber, jurnal, buku, dokumentasi, internet, dan studi pustaka.

\subsection{Metode Pengolahan dan Analisis Data}

Penulis menerapkan metode KPI (Key Performance Indicator) pada sistem penilaian kinerja promotor terhadap product knowledge. Berikut ini adalah prosedur yang dilakukan sebagai berikut:

1. Cara menilai untuk test kuesioner menggunakan google form adalah test pilihan ganda dengan setiap jawaban benar memiliki poin 5 dari 20 soal. Jadi setiap jawaban benar akan dikalikan dengan 5. Maka hasil tersebut akan dijadikan nilai kuesioner.

2. Cara menilai untuk test probing adalah test probing dinilai oleh trainer melalui tabel penilaian yang sudah ditetapkan perusahaan. Tabel penilaian terdiri dari kalimat pembuka dengan nilai maksimalnya 25 , desain dengan nilai maksimalnya 20 , performa dengan nilai maksimalnya 20 , kamera dengan nilai maksimalnya 20, Oppo band dengan nilai maksimalnya 10 dan kalimat penawaran bundling Oppo band dengan nilai maksimalnya 5. Semua nilai dari masing-masing tabel tersebut dijumlahkan dengan nilai maksimal adalah 100 dan hasil tersebut akan dijadikan nilai test probing.

3. Cara menilai untuk test komparasi adalah test komparasi dinilai oleh trainer melalui tabel penilaian yang sudah ditetapkan oleh perusahaan, Tabel penilaian ini terdiri dari merek kompetitor Hp Oppo yang sejenis dengan tipe Reno 5F. Ada 7 tabel merek kompetitor yaitu Realme 8, Samsung A32 (6GB), Samsung A32 (8GB), Vivo V20 SE, Realme 7, Samsung A31, dan Xiaomi Poco X3 NFC. Nilai maksimal dari setiap tabel adalah 20. Promotor harus memilih 5 tabel kompetitor dan nilai maksimal dari nilai komparasi adalah 100.

4. Penjualan berisi data target penjualan dan pencapaian penjualan bulan Maret 2021.

Setelah melakukan input sistem akan melakukan proses yang terdiri dari beberapa tahap yaitu:

1. Mengeloah setiap nilai dari setiap indikator yaitu dengan menggunakan rumus, Skor KPI = (A/T)*B dimana A itu adalah Achivement (Pencapaian), $\mathrm{T}$ itu adalah Target dan B adalah Bobot KPI.

2. Setelah mendapatkan hasil skor KPI kemudian dirangkingkan dari skor akhir KPI tertinggi sampai yang terendah. Setiap promotor yang mendapatkan skor KPI 100 akan mendapatkan Reward sebesar Rp 200.000 sesuai dengan ketentuan perusahaan.

Perancangan Sistem Informasi Penilaian Kinerja Promotor terhadap Product Knowledge Menggunakan Metode Key Performance Indicator (Studi Kasus : PT. World Innovative Telecommunication)- 


\section{HASIL DAN PEMBAHASAN}

4.1. Hasil Perhitungan KPI

Tabel 1. Tabel Kententuan Penilaian

\begin{tabular}{|l|l|l|}
\hline \multirow{2}{*}{ Nama Kriteria } & \multicolumn{2}{|l|}{ Oppo Reno5 F } \\
\cline { 2 - 3 } Kuesioner & Target & Bobot \\
\hline Probing & 95 & 10 \\
\hline Komparasi & 95 & 30 \\
\hline Penjualan & 95 & 10 \\
\hline & $\begin{array}{l}\text { Disesuaikan } \\
\text { dengan } \\
\text { perusahaan }\end{array}$ & 50 \\
\hline
\end{tabular}

Tabel 2. Tabel Perhitungan Skor KPI Kuesioner

\begin{tabular}{|l|l|l|}
\hline \multirow{2}{*}{ Nama Promotor } & \multicolumn{2}{|l|}{ Skor KPI Kuesioner } \\
\cline { 2 - 3 } TIYA DWIYANA & 100 & 10 \\
\hline FUAD AMIN & 100 & 10 \\
\hline SRI RAHAYU PUTRI & 100 & 10 \\
\hline ALIPIYA APRIYANI & 100 & 10 \\
\hline $\begin{array}{l}\text { SRI ANDANI } \\
\text { SUNENGSIH }\end{array}$ & 95 & 10 \\
\hline LIPANA EVA & 90 & 9 \\
\hline ANISYA NURAVIFA & 100 & 10 \\
\hline NOVI NOVITA & 100 & 10 \\
\hline SYAMSUL MA'ARIF & 100 & 10 \\
\hline ASEP NASRULLOH & 100 & 10 \\
\hline
\end{tabular}

Contoh perhitungan dari kuesioner adalah TIYA DWIYANA mendapatkan pencapaian kuesioner 100 maka dengan rumus skor KPI $=(\mathrm{A} / \mathrm{T}) * \mathrm{~B}$, hasilnya adalah skor KPI $=(100 / 95)^{*} 10$. Skor KPI adalah 10.

Tabel 3. Tabel Perhitungan Skor KPI Probing

\begin{tabular}{|l|l|l|}
\hline \multirow{2}{*}{ Nama Promotor } & \multicolumn{2}{|l|}{ Skor KPI Probing } \\
\cline { 2 - 3 } & Pencapaian & Skor KPI \\
\hline TIYA DWIYANA & 95 & 30 \\
\hline FUAD AMIN & 95 & 30 \\
\hline SRI RAHAYU PUTRI & 90 & 28 \\
\hline ALIPIYA APRIYANI & 90 & 28 \\
\hline SRI ANDANI SUNENGSIH & 75 & 23 \\
\hline LIPANA EVA & 80 & 25 \\
\hline ANISYA NURAVIFA & 100 & 30 \\
\hline
\end{tabular}




\begin{tabular}{|l|l|l|}
\hline \multirow{2}{*}{ Nama Promotor } & \multicolumn{2}{|l|}{ Skor KPI Probing } \\
\cline { 2 - 3 } & Pencapaian & Skor KPI \\
\hline NOVI NOVITA & 95 & 30 \\
\hline SYAMSUL MA'ARIF & 95 & 30 \\
\hline ASEP NASRULLOH & 95 & 30 \\
\hline
\end{tabular}

Contoh perhitungan dari probing adalah TIYA DWIYANA mendapatkan pencapaian probing 95 maka dengan rumus skor KPI $=(\mathrm{A} / \mathrm{T}) * \mathrm{~B}$ hasilnya adalah skor KPI $=(95 / 95) * 30$. Skor KPI adalah 30.

Tabel 4. Tabel Perhitungan Skor KPI Komparasi

\begin{tabular}{|l|l|l|}
\hline \multirow{2}{*}{ Nama Promotor } & \multicolumn{2}{|l|}{ Skor KPI Komparasi } \\
\cline { 2 - 3 } & Pencapaian & Skor KPI \\
\hline TIYA DWIYANA & 100 & 10 \\
\hline FUAD AMIN & 90 & 9 \\
\hline SRI RAHAYU PUTRI & 100 & 10 \\
\hline ALIPIYA APRIYANI & 70 & 7 \\
\hline SRI ANDANI SUNENGSIH & 90 & 9 \\
\hline LIPANA EVA & 80 & 8 \\
\hline ANISYA NURAVIFA & 80 & 8 \\
\hline NOVI NOVITA & 80 & 8 \\
\hline SYAMSUL MA'ARIF & 90 & 9 \\
\hline ASEP NASRULLOH & 90 & 9 \\
\hline
\end{tabular}

Contoh perhitungan dari komparasi adalah TIYA DWIYANA mendapatkan pencapaian komparasi 100 maka dengan rumus skor KPI $=(\mathrm{A} / \mathrm{T}) * \mathrm{~B}$ hasilnya adalah skor KPI $=(100 / 95) * 10$. Skor KPI adalah 10.

Tabel 5. Tabel Target Penjualan Promotor

\begin{tabular}{|l|l|l|}
\hline \multirow{2}{*}{ Nama Promotor } & \multicolumn{2}{|l|}{ Penjualan Maret 2021 } \\
\cline { 2 - 3 } & Target & Pencapaian \\
\hline TIYA DWIYANA & 140 & 140 \\
\hline FUAD AMIN & 182 & 164 \\
\hline SRI RAHAYU PUTRI & 155 & 137 \\
\hline ALIPIYA APRIYANI & 217 & 205 \\
\hline SRI ANDANI SUNENGSIH & 155 & 152 \\
\hline LIPANA EVA & 252 & 251 \\
\hline ANISYA NURAVIFA & 133 & 113 \\
\hline
\end{tabular}

Perancangan Sistem Informasi Penilaian Kinerja Promotor terhadap Product Knowledge Menggunakan Metode Key Performance Indicator (Studi Kasus : PT. World Innovative Telecommunication)-

(Genesis Angelia, Petrus Sokibi, Rifqi Fahrudin) 


\begin{tabular}{|l|l|l|}
\hline \multirow{2}{*}{ Nama Promotor } & Penjualan Maret 2021 \\
\cline { 2 - 3 } & Target & Pencapaian \\
\hline NOVI NOVITA & 133 & 114 \\
\hline SYAMSUL MA'ARIF & 177 & 142 \\
\hline ASEP NASRULLOH & 177 & 137 \\
\hline
\end{tabular}

Tabel 6. Tabel Perhitungan Skor KPI Penjualan

\begin{tabular}{|l|l|l|}
\hline \multirow{2}{*}{ Nama Promotor } & \multicolumn{2}{l|}{ Skor KPI Penjualan } \\
\cline { 2 - 3 } & $\begin{array}{l}\text { Pencapaia } \\
\text { n }\end{array}$ & Skor KPI \\
\hline TIYA DWIYANA & 140 & 50 \\
\hline FUAD AMIN & 164 & 45 \\
\hline SRI RAHAYU PUTRI & 137 & 44 \\
\hline ALIPIYA APRIYANI & 205 & 47 \\
\hline SRI ANDANI SUNENGSIH & 152 & 49 \\
\hline LIPANA EVA & 251 & 49 \\
\hline ANISYA NURAVIFA & 113 & 42 \\
\hline NOVI NOVITA & 114 & 42 \\
\hline SYAMSUL MA'ARIF & 142 & 40 \\
\hline ASEP NASRULLOH & 137 & 38 \\
\hline
\end{tabular}

Contoh perhitungan dari komparasi adalah TIYA DWIYANA mendapatkan pencapaian penjualan 140 maka dengan rumus skor $\mathrm{KPI}=(\mathrm{A} / \mathrm{T}) * \mathrm{~B}$ hasilnya adalah skor KPI $=(140 / 140) * 50$. Skor KPI adalah 50.

Tabel 7. Tabel Total Skor KPI dan Reward

\begin{tabular}{|l|l|l|}
\hline \multirow{2}{*}{ Nama Promotor } & \multicolumn{2}{|l|}{$\begin{array}{l}\text { Total Skor KPI dan } \\
\text { Reward }\end{array}$} \\
\cline { 2 - 3 } & $\begin{array}{l}\text { Total Skor } \\
\text { KPI }\end{array}$ & Reward \\
\hline TIYA DWIYANA & 100 & $\begin{array}{l}\text { Rp } \\
200.000\end{array}$ \\
\hline FUAD AMIN & 94 & 0 \\
\hline SRI RAHAYU PUTRI & 92 & 0 \\
\hline ALIPIYA APRIYANI & 92 & 0 \\
\hline SRI ANDANI SUNENGSIH & 91 & 0 \\
\hline LIPANA EVA & 91 & 0 \\
\hline ANISYA NURAVIFA & 90 & 0 \\
\hline NOVI NOVITA & 90 & 0 \\
\hline SYAMSUL MA'ARIF & 89 & 0 \\
\hline ASEP NASRULLOH & 87 & 0 \\
\hline
\end{tabular}


Contoh perhitungan total skor KPI adalah menjumlahkan skor KPI dari setiap indikator. Jika promotor mendapatkan skor 100 maka akan mendapatkan reward Rp. 200.000. TIYA DWIYANA mendapatakan skor KPI dari setiap indikator adalah $10+30+10+50$ maka hasilnya adalah 100. Maka TIYA berhak mendapatkan reward Rp. 200.000.

Berikut ini Use Case Diagram:

1. Promotor

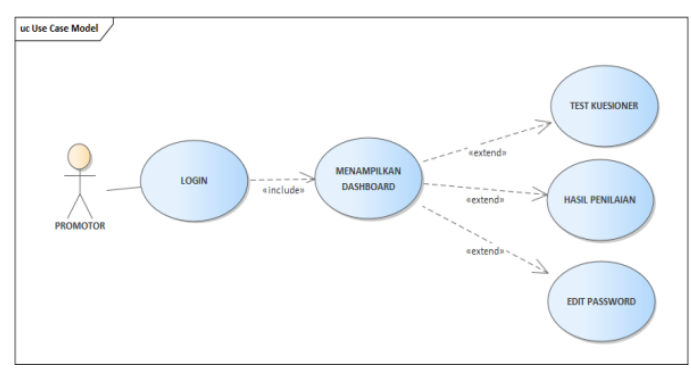

Gambar 1. Use Case Diagram Promotor

2. Trainer

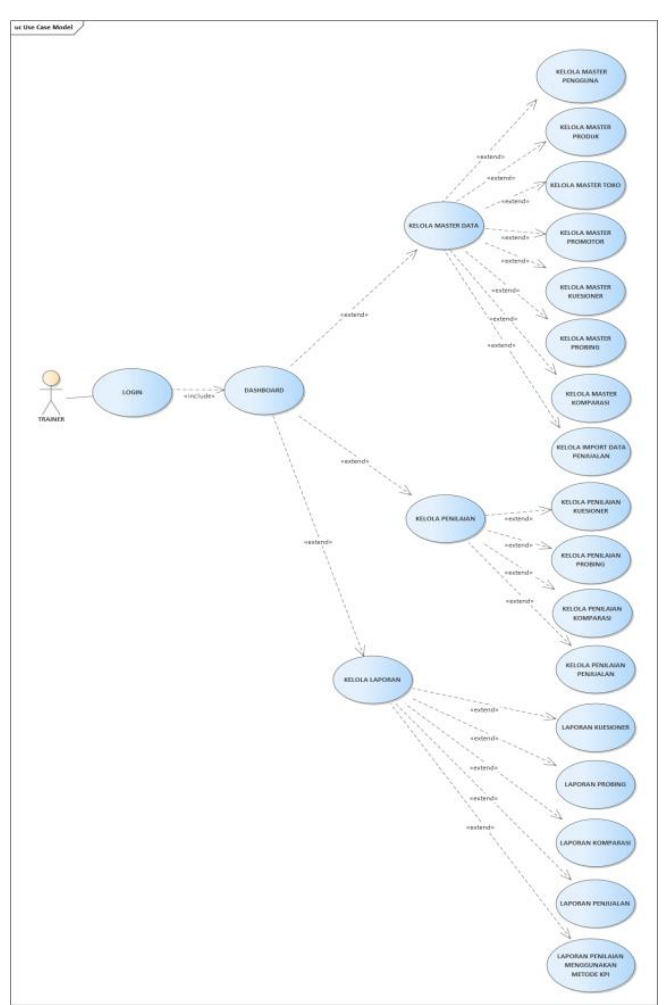

Gambar 2. Use Case Diagram Trainer

Perancangan Sistem Informasi Penilaian Kinerja Promotor terhadap Product Knowledge Menggunakan Metode Key Performance Indicator (Studi Kasus : PT. World Innovative Telecommunication)-

(Genesis Angelia, Petrus Sokibi, Rifqi Fahrudin) 
3. Regional Manager

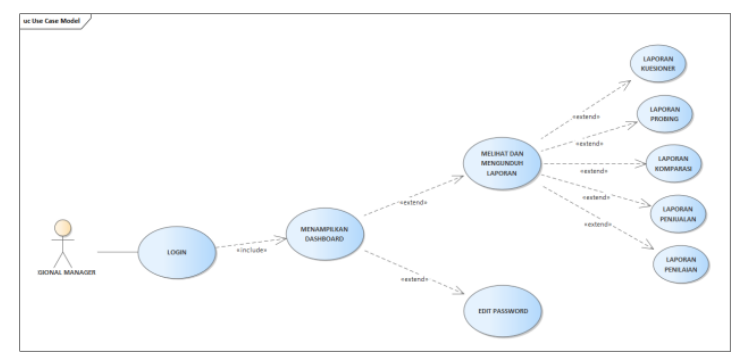

Gambar 3. Use Case Diagram Regional Manager

Berikut ini adalah tampilan program:

1. Tampilan login

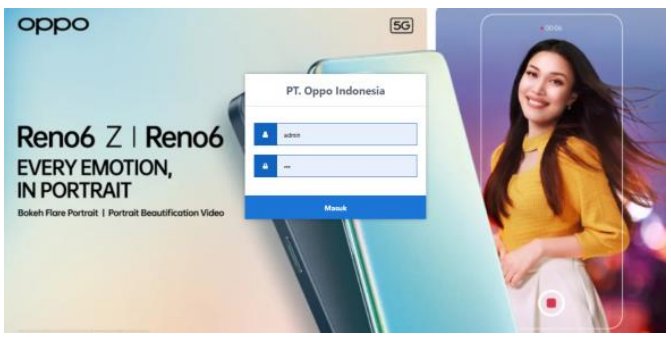

Gambar 4. Tampilan Login

2. Tampilan Master Produk

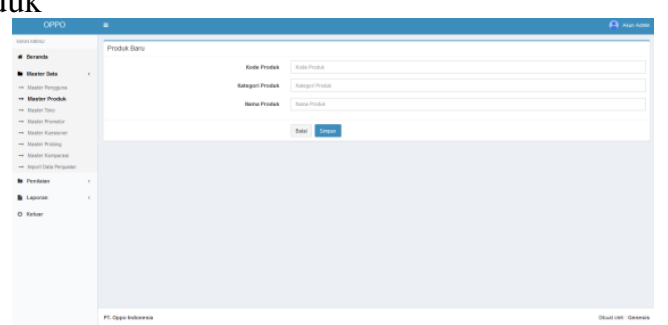

Gambar 5. Master Produk

3. Tampilan Master Promotor

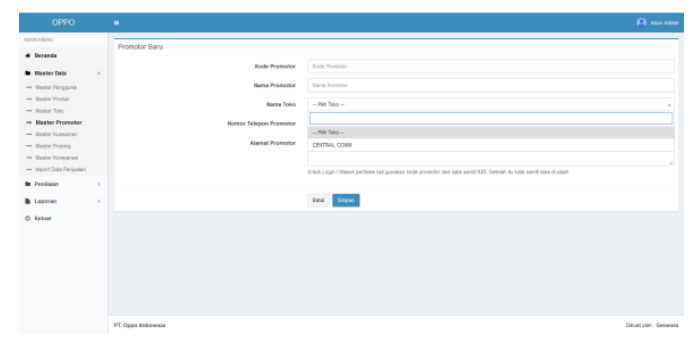

Gambar 6. Master Promotor 
4. Tampil Master Toko

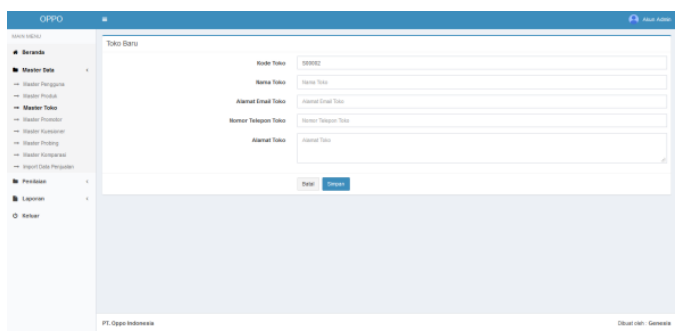

Gambar 7. Master Toko

5. Tampil Master Kuesioner

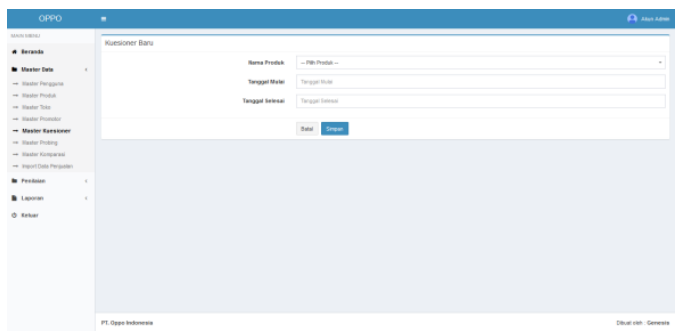

Gambar 8. Master Kuesioner

6. Tampil Master Probing

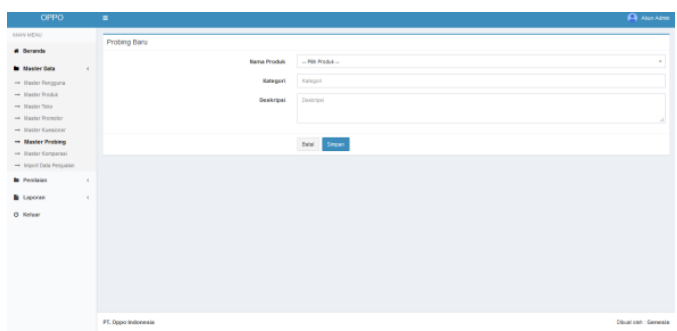

Gambar 9. Master Probing

7. Tampil Penilaian Probing

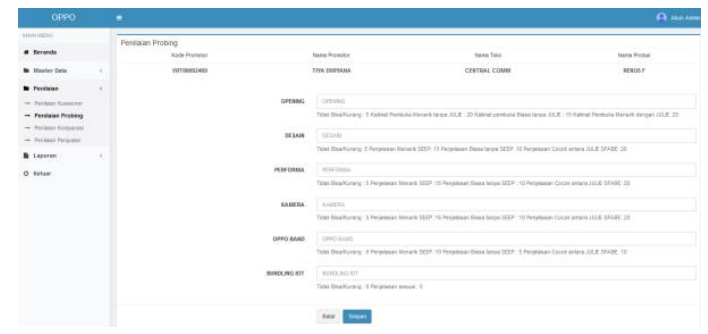

Gambar 10. Penilaian Probing

Perancangan Sistem Informasi Penilaian Kinerja Promotor terhadap Product Knowledge Menggunakan Metode Key Performance Indicator (Studi Kasus : PT. World Innovative Telecommunication)-

(Genesis Angelia, Petrus Sokibi, Rifqi Fahrudin) 
8. Tampil Penilaian Komparasi

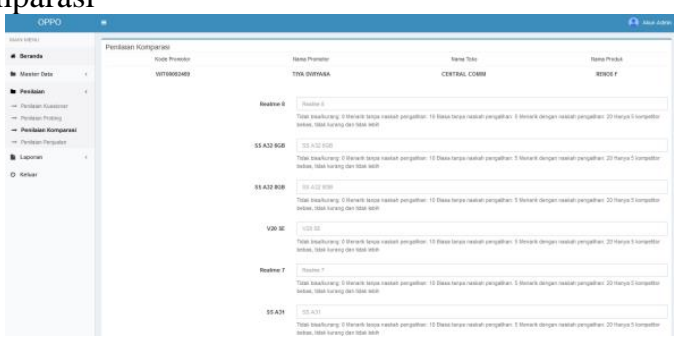

Gambar 11. Penilaian Komparasi

9. Tampil Laporan KPI

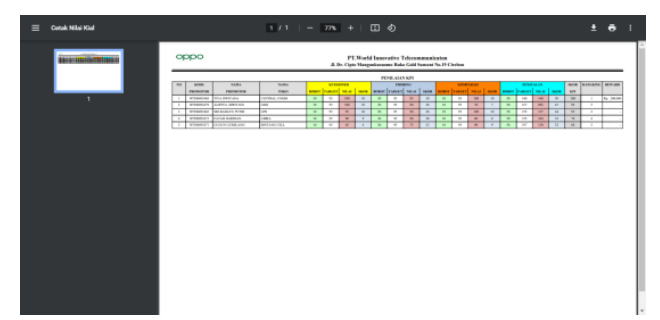

Gambar 12. Laporan KPI

\section{KESIMPULAN}

\subsection{Kesimpulan}

Berdasarkan masalah dan pembahasan analisis yang telah diuraikan oleh penulis diatas maka dapat diambil kesimpulan terhadap aplikasi penilaian kinerja promotor terhadap product knowledge di PT. World Innovative Telecommunication sebgai berikut:

1. Aplikasi ini memiliki sistem penilaian yang efektif dan efisien bagi promotor yaitu promotor dapat melihat hasil penilaian dari setiap kriteria sedangkan untuk trainer yaitu mempermudah dalam melakukan penilaian dan regional manager dapat melihat hasil kinerja promotor terhadap product knowledge.

2. Aplikasi ini memiliki 4 kriteria dan bobot dalam sistem penilaian yaitu kuesioner (10), probing(30), komparasi (10) dan penjualan (50).

3. Penerapan metode Key Performance Indikator (KPI) ini dapat menunjang dalam pengambilan keputusan penilaian kinerja promotor.

4. Menghasilkan laporan penilaian product knowlegde promtor dimana setiap promotor yang mendapatkan skor kpi 100 akan mendapatkan reward Rp.200.000 dan setifikat.

\subsection{Saran}

Adapun saran-saran yang penulis berikan untuk pengembangan aplikasi ini selanjutnya adalah:

1. Kriteria dalam penilaian kinerja promotor terhadap product knowledge dapat dikembangkan.

2. Aplikasi dapat dikembangkan menjadi aplikasi mobile.

3. Pengembangan fitur aplikasi yaitu video call dalam penilaian probing dan komparasi pada saat role play.

4. Dikembangkan dengan mengkomparasi sistem penilaian dengan Oppo pusat. 


\section{DAFTAR PUSTAKA}

[1] Sokibi Petrus dan Apriyanto Noer Setiawan," Sistem Pendukung Keputusan Penilaian Kinerja Karyawan PT Harjamukti Jaya Mandiri Menggunakan Metode Simple Additive Weighting”, Jatisi, vol. 5, no. 1, pp. 109-118, September 2018..

[2] Soemohadiwidjojo, Arini T, Panduan Praktis Menyusun KPI. Jakarta: Raih Asa Sukses, 2015.Ratnawati, Christina. 2011. "Pengaruh Relationship Marketing dan Kualitas Pelayanan Rawat Inap Terhadap Loyalitas Pasien Rumah Sakit Ngesti Waluyo Parakan". Semarang: Jurusan Manajemen Fakultas Ekonomi Universitas Negeri Semarang.

[3] A. Hariyanto, Membuat Web Profil Sekolah + PPDB Online. Yogyakarta: CV. Lokomedia, 2015.

[4] Adin, Sutardi, Tajidun, "SPK Penilaian Dan Pemberian Bonus Salesman Pada PT Matakar Kendari Dengan Menggunakan Metode Profile Matching," Jurnal SemanTIK, vol. 3, no. 1, pp. 199-208, Januari 2017.Kotler \& Amstrong. 2006. The Principle of Marketing Management. USA: Prentice Hall.

[5] Supono, dan Vidiandry, Pemrograman Web Dengan Menggunakan Php dan Framework Codeigniter. Yogyakarta: Deepublish, 2016.Schiffman, Leon G and Leslie Lazar Kanuk. 2004. Customer Behaviour. Eight Edition. Pearson Educational International.

[6] M. Hadi, Sistem Pengolahan Tabungan Siswa Berbasis Java Dekstop. Bandung: Universitas Telkom, 2015.Santoso Singgih. 2012. Statistik Parametrik. Jakarta: Elek Media Komputindo.

Perancangan Sistem Informasi Penilaian Kinerja Promotor terhadap Product Knowledge Menggunakan Metode Key Performance Indicator (Studi Kasus : PT. World Innovative Telecommunication)- 